\title{
Effect of Plasma Treatment on Moisture Management Properties and Drying Behavior of Polyester and Blend Fabrics for Sportswear Application
}

\author{
Mayur Basuk ${ }^{1}$, Smita Bait ${ }^{1}$, Saptarshi Maiti ${ }^{2}$ and RV Adivarekar ${ }^{2 *}$ \\ ${ }^{1}$ Wool Research Association, India \\ ${ }^{2}$ Department of Fibres and Textile Processing Technology, Institute of Chemical Technology, Matunga, Mumbai, India
}

Submission: May 03, 2018; Published: May 31, 2018

*Corresponding author: Adivarekar RV, Department of Fibres and Textile Processing Technology, Institute of Chemical Technology, Matunga, Mumbai, India, Tel: 022-33612801/09833408172; Email: rv.adivarekar@ictmumbai.edu.in

\begin{abstract}
The hygienic and comfort properties of fabrics for clothing are basically determined by their electrifiability and ability to absorb moisture, i.e. the hygroscopicity and capillarity, which are quantitative characteristics of the hydrophilicity of materials. Unfortunately, the most common synthetic fibre, Polyester exhibits high electrifiability and low hydrophilicity, which makes it unsuitable for fabrication of fabrics with properties close to cellulosic fibre and significantly restricts the area of their application. However, now a days, it is more preferable in the active sportswear due to its excellent physical properties like abrasion resistance, strength etc. and low cost. The present study aims at increasing the hydrophilicity of polyester and polyester blends by combination of plasma modification and chemical treatment. Surface modification of the developed fabrics is carried out by di-electric barrier discharge plasma in presence of air and subsequently the fabrics are subjected to chemical treatment to impart hydrophilic property to make it suitable for active sportswear. The moisture management properties, drying rate and air permeability, abrasion resistance etc. of these fabrics are evaluated.
\end{abstract}

Keywords: Sportswear; Hydrophilicity; Polyester; Plasma modification; Moisture management

Abbreviations: DBD: Di-Electric Barrier Discharge; OWTC: Accumulative One-Way Transport Capacity; OMMC: Overall Moisture Management Capability

\section{Introduction}

Polyester fiber is one of the most widely consumed fibers (about 70\%) in sportswear application but its hydrophobic properties causes discomfort to the wearer [1]. Hydrophobic nature of polyester can be a disadvantage for certain applications like moisture management properties, dyeing, finishing, detergency, etc. [2]. During sports activity, wearer perspires a lot and it is essential that the perspiration should transfer to the outer surface of the fabric from where it gets evaporated and wearer feels dry and comfortable. Physical or chemical modification of polyester to make it more hydrophilic is therefore desirable for certain performance characteristics. Surface modification of polyester for hydrophilicity can be achieved by application of adsorbing polymers on the polyester surface [3].
Moisture management is one of the important property in Active sportswear fabrics with respect to thermo-physiological comfort. Therefore, it is essential to increase the hydrophilicity of polyester. In moisture management fabrics, the body perspiration is transported away from the skin to the outer surface of fabric where it can evaporate quickly in order to accomplish the consumer satisfaction of comfort [4]. To achieve such moisture management, the structural design and quality of fibers are modified so that the textile products can have good performance in absorbing, transporting, and dissipating moisture [5,6]. According to The Tai Lee Textiles Company, moisture management is related to wickability of the fabric which mainly depends upon the type of fiber and its chemical characteristics, diameter of the fiber, diameter of the yarn, yarn regularity, surface structure of the fabric, fabric construction, 


\section{Current Trends in Fashion Technology \& Textile Engineering}

weave pattern, the cover factor, fabric weight etc. [7]. Das et al. [8] also described that moisture management can be enhanced through a suitable chemical treatment or coating [8].

It is evident that fiber type, yarn properties, fabric structure, finishing treatments affects the clothing comfort. The use of blended fibre combinations in sportswear has grown in the past decade as brands attempt to improve function and comfort using different fiber blends. The use of blending technologies and the chemical finishing available for sportswear will continue to provide a source of innovation for sportswear products. Therefore, the present study aims to investigate the moisture management properties and drying rate of commercial garments, and 16 knitted fabrics developed for sportswear application, composed of plasma and chemically modified polyester and polyester blend fabrics.

Table 1: Construction parameters of polyester and polyester blend fabrics.

\begin{tabular}{|c|c|c|c|c|c|}
\hline S. No. & Fabric Parameters & K1 & K2 & K3 & K4 \\
\hline & & Polyester & Polyester/Lycra & Polyester & Polyester/Cotton \\
\hline 2. & Blend Composition \% & 100 & $95 / 5$ & 100 & $68 / 42$ \\
\hline 3. & $\begin{array}{l}\text { Polyester filament } \\
\text { denier }\end{array}$ & $2 \mathrm{D}$ & $2 \mathrm{D}$ & $2 \mathrm{D}$ & $2 \mathrm{D}$ \\
\hline 4. & Cotton/Lycra count & -- & 20 D Lycra (Spandex) & -- & $60 \mathrm{Ne}$ \\
\hline 5 & Yarn Count & 85 D/48 filament filament & 85 D/48 filament & 85 D/48 filament & $85 \mathrm{D} / 48$ \\
\hline 6. & Wales per $\mathrm{cm}$ & 14 & 14 & 14 & 14 \\
\hline 7. & Course per $\mathrm{cm}$ & 14 & 12 & 18 & 18 \\
\hline 8. & $\begin{array}{l}\text { Grams per square } \\
\text { meter (GSM) }\end{array}$ & 114.0 & 123.0 & 298.0 & 298.0 \\
\hline 9. & Stitch Length (in mm) & 2.5 & 2.7 & 4.5 & 4.5 \\
\hline 10. & Knit Structure & Single layer Knitted fabric & Single layer Knitted fabric & $\begin{array}{l}\text { Double Layer interlock } \\
\text { Knitted fabric }\end{array}$ & $\begin{array}{l}\text { Bi layer interlock } \\
\text { Knitted fabric }\end{array}$ \\
\hline
\end{tabular}

Table 2: Construction parameters of commercial garments.

\begin{tabular}{|c|c|c|c|c|}
\hline \multirow[t]{2}{*}{ S. No. } & \multirow[t]{2}{*}{ Test Parameters } & \multicolumn{3}{|c|}{ Results } \\
\hline & & $\begin{array}{l}\text { Commercial Garment } \\
\text { (CG-1) }\end{array}$ & $\begin{array}{l}\text { Commercial Garment } \\
\text { (CG-2) }\end{array}$ & Commercial Garment (CG-3) \\
\hline 1 & Application & Bottoms & Top & Top \\
\hline 2 & Blend composition & $100 \%$ polyester & $\begin{array}{c}\text { Cotton - } 26.0 \% \\
\text { Polyester - } 74.0 \%\end{array}$ & $\begin{array}{l}\text { Cotton - } 57.0 \text { Polyester }-43.0 \% \text { (dotted portion) } \\
\text { Cotton - } 59.5 \text { Polyester }-40.5 \% \text { (plain portion) }\end{array}$ \\
\hline 3 & $\begin{array}{c}\text { Count of yarn (in Nm) } \\
\text { (IS 3442) }\end{array}$ & $1 / 150.2$ & $1 / 42.7$ & $1 / 47.5$ \\
\hline 4 & Yarn twist (IS 832) & Texturized yarn & 17.7 & 15.0 \\
\hline 5 & $\begin{array}{l}\text { Fiber Denier ( ASTM D } \\
\text { 1577) }\end{array}$ & 0.8 & 1.5 & 1.5 \\
\hline 6 & Weave (visual) & Double jersey & Single jersey & Single jersey \\
\hline 7 & GSM & 161.59 & 103.27 & $\begin{array}{c}145.17 \text { (dotted portion) } \\
157.14 \text { (plain portion) }\end{array}$ \\
\hline 8 & Thickness (in mm) & 0.414 & 0.525 & $\begin{array}{l}0.49 \text { (dotted portion) } \\
0.519 \text { (plain portion) }\end{array}$ \\
\hline 9 & Wales per inch & 112.75 & 34.25 & 35.25 \\
\hline & Course per inch & 126.25 & 54.75 & 58.5 \\
\hline
\end{tabular}




\section{Current Trends in Fashion Technology \& Textile Engineering}

\section{Plasma treatment of developed fabrics}

To study the effect of plasma treatment on moisture management properties and drying behavior of knitted fabrics, a Di-electric Barrier Discharge (DBD) plasma chamber was employed for plasma treatment of polyester fabric at different duration keeping voltage and electrode spacing constant. Air was used as non-polymerizing gas for plasma treatment. Undyed microfilament polyester fabric of sample size $40 \mathrm{~cm}$ width and $50 \mathrm{~cm}$ length was spread between the two electrodes and then plasma treatment was carried out. The treatments were given only on one side of the fabric i.e., inner side of the garment to be worn. Table 3 indicates the details of plasma trials conducted on single layer and double layer knitted fabrics.

Table 3: Plasma trials conducted on polyester and polyester blend fabrics.

\begin{tabular}{|c|c|c|}
\hline S. No. & Sample Code & $\begin{array}{c}\text { Duration of plasma treatment in mins (at } 4.0 \mathrm{KV} \text { Voltage and } 3 \mathrm{~mm} \text { Electrode } \\
\text { Spacing) }\end{array}$ \\
\hline 1 & K1 - UT & - \\
\hline 2 & $\mathrm{~K} 1-\mathrm{A}$ & $5 \mathrm{~min}$ \\
\hline 3 & $\mathrm{~K} 1-\mathrm{B}$ & $10 \mathrm{~min}$ \\
\hline 4 & $\mathrm{~K} 1-\mathrm{C}$ & $15 \mathrm{~min}$ \\
\hline 5 & K2 - UT & - \\
\hline 6 & $\mathrm{~K} 2-\mathrm{A}$ & $5 \mathrm{~min}$ \\
\hline 7 & $\mathrm{~K} 2-\mathrm{B}$ & $10 \mathrm{~min}$ \\
\hline 8 & $\mathrm{~K} 2-\mathrm{C}$ & $15 \mathrm{~min}$ \\
\hline 9 & K3 - UT & - \\
\hline 10 & K3 - A & $5 \mathrm{~min}$ \\
\hline 11 & K3 - B & $10 \mathrm{~min}$ \\
\hline 12 & $\mathrm{~K} 3-\mathrm{C}$ & $15 \mathrm{~min}$ \\
\hline 13 & K4 - UT & - \\
\hline 14 & $\mathrm{~K} 4-\mathrm{A}$ & $5 \mathrm{~min}$ \\
\hline 15 & K4 - B & $10 \mathrm{~min}$ \\
\hline 16 & $\mathrm{~K} 4-\mathrm{C}$ & $15 \mathrm{~min}$ \\
\hline
\end{tabular}

\section{Application of moisture management finish}

To remove the impurities like lubricants and antistatic agents, $100 \%$ polyester and Modal/Cotton, Modal/Polyester woven and knitted fabrics were scoured using $1 \mathrm{gpl}$ nonionic surfactant (Archroma) at $65{ }^{\circ} \mathrm{C}$ for $30 \mathrm{~min}$ followed by rinsing, hydro extraction and drying at room temperature. These scoured fabrics were then used for moisture management finish. 30gpl Hydrophillic Softener (Archroma) which is a modified polyester copolymer based nonionic chemical; was used for finishing of polyester fabrics with $60 \%$ weight pickup. The trials were conducted using pad - dry - cure method on laboratory pad dry cure machine (R. B. Electronics and Electrical Pvt. Ltd., Mumbai); curing was carried out at $120^{\circ} \mathrm{C}$ for $4 \mathrm{~min}$.

\section{Results \& Discussion}

\section{Moisture management properties}

Fabric liquid moisture transport properties in multi dimensions, called moisture management properties significantly influence human perceptions of moisture sensation. Moisture management tester has been developed by SDL Atlas to evaluate textile moisture management properties. This method can be used to quantitatively measure liquid moisture transfer in one step in a fabric in multiple directions. Moisture spreads on both surface of the fabric and transfer from one surface to the opposite. Here ten indices are introduced to characterize the liquid moisture management properties of fabric. It measures electrical conductivity changes as a test solution migrates across the top of, through, and across the bottom of the test specimen. Factors affecting this movement include fabric water repellency, water resistance, and water absorption, and fiber and yarn wicking properties. Perspiration is mimicked with TM 195. The results obtained with this test method are based on water resistance, water repellency and water absorption characteristics of the fabric structure, including the fabric's geometric and internal structure along with the wicking characteristics of its fibers and yarns. 


\section{Current Trends in Fashion Technology \& Textile Engineering}

\section{Moisture management tester indices}

The indices of the MMT that are used to characterize the moisture management properties of a fabric are as mentioned below:

i. Wetting time top (WT)

ii. Wetting time bottom $\left(\mathrm{WT}_{\mathrm{b}}\right)$

iii. Top absorption rate $\left(\mathrm{MAR}_{\mathrm{t}}\right)$

iv. Bottom absorption rate $\left(\mathrm{MAR}_{\mathrm{b}}\right)$

v. Top maximum wetted radius $\left(\mathrm{MWR}_{\mathrm{t}}\right)$

vi. Bottom maximum wetted radius $\left(\mathrm{MWR}_{\mathrm{b}}\right)$ vii. Top spreading speed $\left(\mathrm{SS}_{\mathrm{t}}\right)$

viii. Bottom spreading speed $\left(\mathrm{SS}_{\mathrm{b}}\right)$

ix. Accumulative One-Way Transport Capacity (OWTC)

x. Overall Moisture Management Capability (OMMC) $[9,10]$.

The OWTC is the difference of accumulative moisture content between the two surfaces of fabric. The OWTC reflects the oneway liquid transport capacity from the top (inner) surface to the bottom (outer) surface of the fabric Table 4. The OMMC is an index indicating the overall capacity of the fabric to manage the transport of liquid moisture, which includes three aspects:

Table 4: Grading of MMT Indices.

\begin{tabular}{|c|c|c|c|c|c|c|}
\hline & & & & Grade & & \\
\hline & & 1 & $\boldsymbol{P}$ & ? & 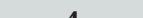 & 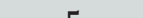 \\
\hline & & $\geq 120$ & $20-119$ & $5-19$ & $3-5$ & $<3$ \\
\hline & & No wetting & Slow & Medium & Fast & Very fast \\
\hline & & $\geq 120$ & $20-119$ & $5-19$ & $3-5$ & $<3$ \\
\hline & & No wetting & Slow & Medium & Fast & Very fast \\
\hline & & $0-10$ & $10-30$ & $30-50$ & $50-100$ & $>100$ \\
\hline & & Very Slow & Slow & Medium & Fast & Very Fast \\
\hline & & $0-10$ & $10-30$ & $30-50$ & $50-100$ & $>100$ \\
\hline & & Very Slow & Slow & Medium & Fast & Very Fast \\
\hline & & $0-7$ & $7-12$ & $12-17$ & $17-22$ & $>22$ \\
\hline & & No wetting & Small & Medium & Large & Very Large \\
\hline 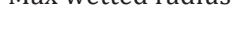 & & $0-7$ & $7-12$ & $12-17$ & $17-22$ & $>22$ \\
\hline & & No wetting & Small & Medium & Large & Very Large \\
\hline & & $0-1$ & $1-2$ & $2-3$ & $3-4$ & $>4$ \\
\hline & & Very Slow & Slow & Medium & Fast & Very Fast \\
\hline & & $0-1$ & $1-2$ & $2-3$ & $3-4$ & $>4$ \\
\hline & & Very Slow & Slow & Medium & Fast & Very Fast \\
\hline & & $<-50$ & $-50-100$ & $100-200$ & $200-400$ & $>400$ \\
\hline & & Poor & Fair & Good & Very Good & Excellent \\
\hline & & $0-0.2$ & $0.2-0.4$ & $0.4-0.6$ & $0.6-0.8$ & $>0.8$ \\
\hline & & Poor & Fair & Good & Very Good & Excellent \\
\hline
\end{tabular}

a. Average moisture absorption rate at the bottom surface;

b. One-way liquid transport capacity;

c. Maximum moisture spreading speed on the bottom surface $[11,12]$.

According to AATCC Test Method 195-2009, the indices are graded and converted from value to grade based on a five point grade scale (1-5), The five grades of indices represent: 1-Poor, 2Fair, 3- Good, 4- Very Good, 5- Excellent. Table 1 shows the range of values converted into grades.

The moisture management properties of the commercial garments and developed fabrics in grades are mentioned in Table 5. 


\section{Current Trends in Fashion Technology \& Textile Engineering}

Table 5: MMT results in grades of commercial garments and developed fabrics.

\begin{tabular}{|c|c|c|c|c|c|c|c|c|c|c|}
\hline Fabric & $\mathrm{WT}_{\mathrm{t}}$ & $\mathbf{W T}_{\mathrm{b}}$ & $\mathrm{MAR}_{\mathrm{t}}$ & $\mathrm{MAR}_{\mathrm{b}}$ & $\mathrm{MWR}_{\mathrm{t}}$ & $\mathrm{MWR}_{\mathrm{b}}$ & $\mathrm{SS}_{\mathrm{t}}$ & $\mathrm{SS}_{\mathrm{b}}$ & OWTC & OMMC \\
\hline $\begin{array}{c}\text { Commercial } \\
\text { garment (CG-1) }\end{array}$ & 5 & 5 & 3.5 & 3.5 & 5 & 5 & 5 & 5 & 1.5 & 2.5 \\
\hline $\begin{array}{c}\text { Commercial } \\
\text { garment (CG-2) }\end{array}$ & 5 & 4.5 & 4 & 4 & 5 & 5 & 5 & 5 & 1.5 & 2.5 \\
\hline $\begin{array}{c}\text { Commercial } \\
\text { garment (CG-3) }\end{array}$ & 4.5 & 4.5 & 3.5 & 3.5 & 5 & 5 & 5 & 5 & 1.5 & 2.5 \\
\hline K1- Untreated & 5 & 5 & 3 & 3 & 5 & 5 & 5 & 5 & 2 & 3 \\
\hline $\mathrm{K} 1-\mathrm{A}$ & 3 & 5 & 3 & 2 & 4 & 4 & 3 & 5 & 5 & 4 \\
\hline $\mathrm{K} 1-\mathrm{B}$ & 3 & 5 & 3 & 2 & 5 & 4 & 3 & 4 & 4 & 4 \\
\hline $\mathrm{K} 1-\mathrm{C}$ & 3 & 5 & 4 & 2 & 5 & 4 & 4 & 4 & 4 & 4 \\
\hline K2 - Untreated & 5 & 5 & 3 & 3 & 5 & 5 & 5 & 5 & 1 & 2 \\
\hline $\mathrm{K} 2-\mathrm{A}$ & 3 & 5 & 3 & 2 & 4 & 4 & 3 & 5 & 5 & 4 \\
\hline K2 - B & 3 & 5 & 3 & 2 & 4 & 4 & 3 & 4 & 4 & 4 \\
\hline $\mathrm{K} 2-\mathrm{C}$ & 3 & 5 & 4 & 2 & 4 & 4 & 4 & 4 & 4 & 4 \\
\hline K3 - Untreated & 4 & 4 & 2 & 2 & 4 & 5 & 4 & 5 & 2 & 3 \\
\hline K3 - A & 3 & 3 & 3 & 3 & 4 & 5 & 5 & 5 & 5 & 4 \\
\hline K3 - B & 4 & 3 & 3 & 3 & 4 & 5 & 5 & 5 & 5 & 4 \\
\hline $\mathrm{K} 3-\mathrm{C}$ & 4 & 4 & 3 & 2 & 4 & 5 & 4 & 5 & 5 & 4 \\
\hline K4- Untreated & 4 & 4 & 3 & 2 & 5 & 3 & 5 & 3 & 1 & 1 \\
\hline K4 - A & 3 & 3 & 4 & 2 & 5 & 3 & 2 & 4 & 4 & 3 \\
\hline $\mathrm{K} 4-\mathrm{B}$ & 3 & 3 & 4 & 2 & 4 & 3 & 3 & 3 & 4 & 3 \\
\hline $\mathrm{K} 4-\mathrm{C}$ & 3 & 3 & 4 & 4 & 2 & 2 & 2 & 3 & 4 & 3 \\
\hline
\end{tabular}

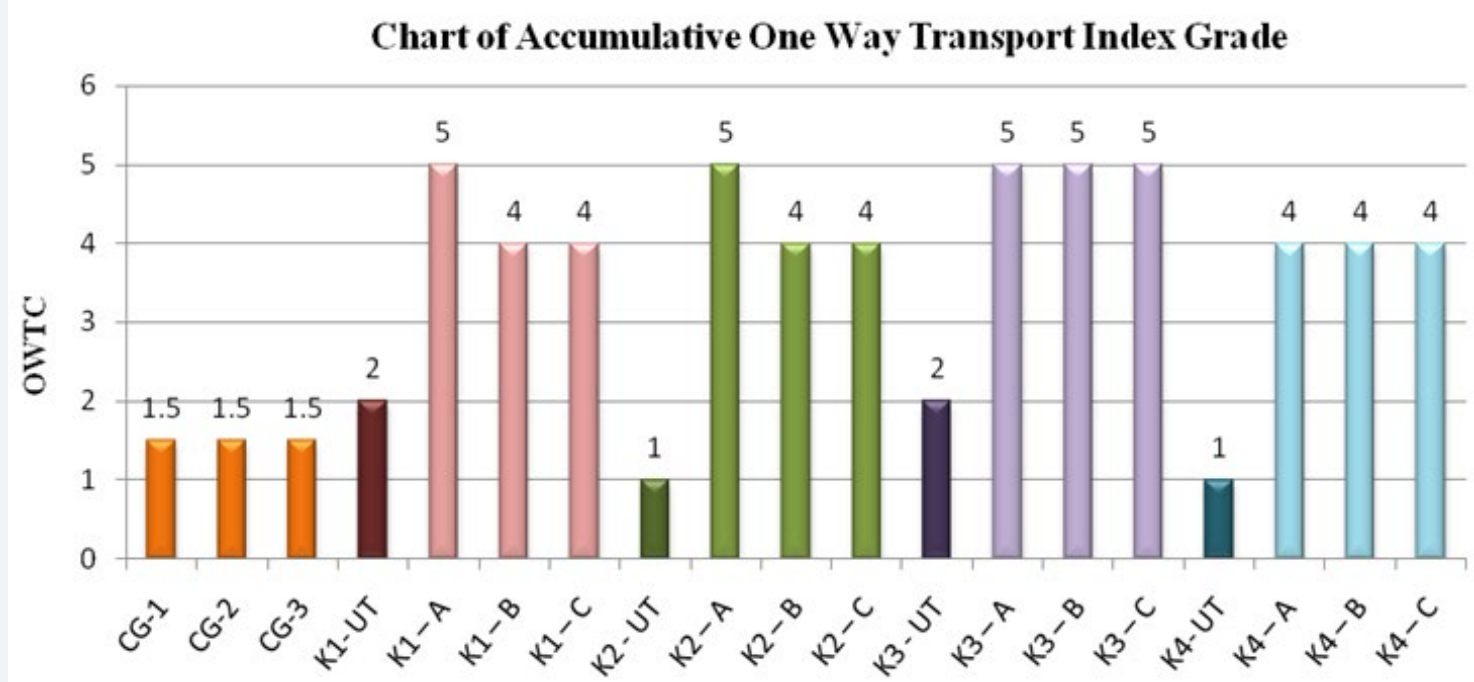

Figure 1: Accumulative One Way Transport Index grades of commercial garments and developed fabrics.

Figure 1 indicates mean grade of accumulative one way transport index for all 3 commercial fabrics and 16 developed fabrics. In non blended fabric 100\% Polyester (K1-UT and K3-
UT) has fair one way transport capacity whereas Polyester/Lycra (K2-UT) blend fabric and Polyester/Cotton blend fabric (K4-UT) shows poor one-way transport capacity. Commercial garment 


\section{Current Trends in Fashion Technology \& Textile Engineering}

has fair OWTC. Plasma and chemically treated Polyester (K1AK1C, K3A- K3C), Polyester/Lycra (K2A- K2C) and Polyester/ Cotton (K4A- K4C) fabric shows very good to excellent one way transport index grade indicating that these fabrics can also be effectively used for sportswear application.

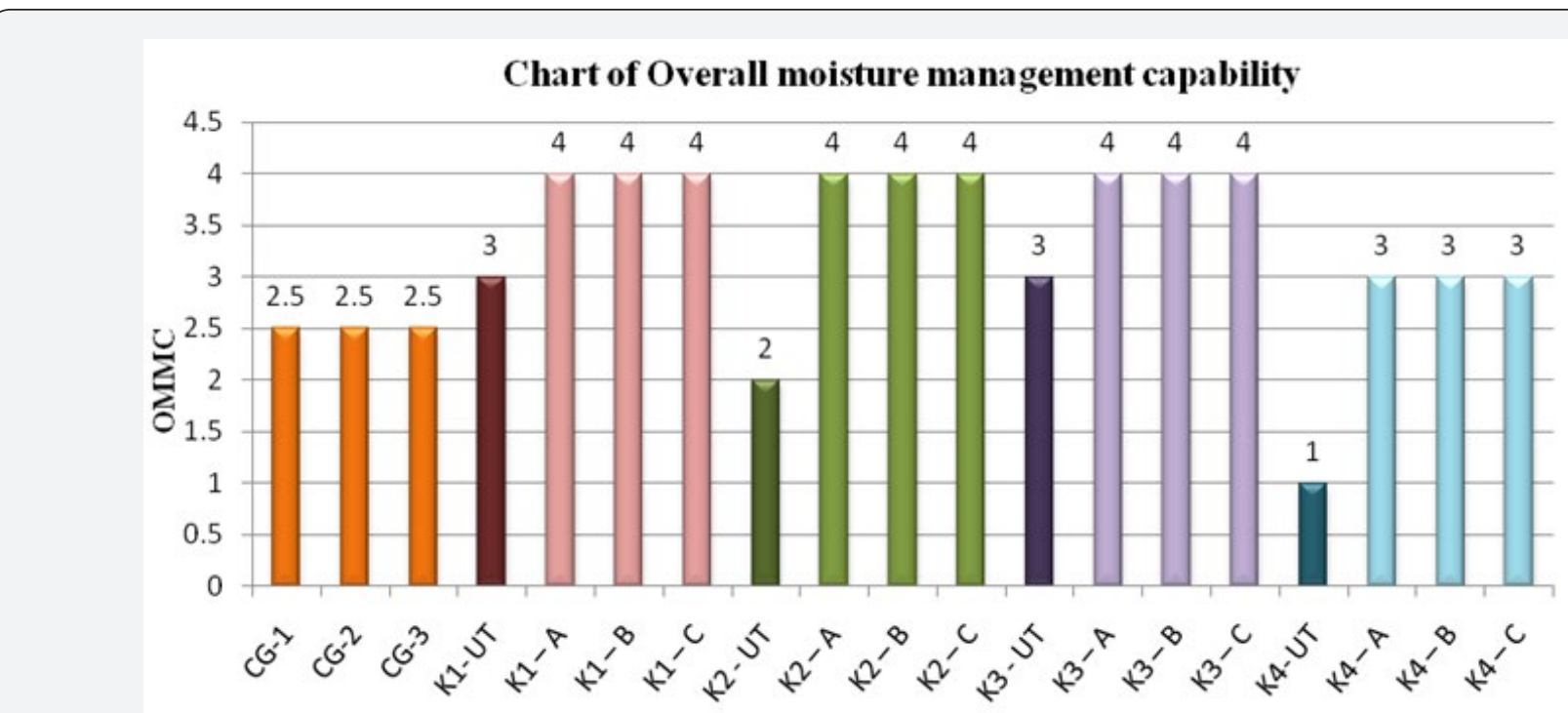

Figure 2: Overall moisture management capability grade of commercial garments and developed fabrics.

Figure 2 indicates overall moisture management capability for all 3 commercial fabrics and 16 developed fabrics. 100\% Polyester (K1-UT and K3-UT) has good OMMC grades. Whereas Polyester/Cotton blend fabric (K4-UT) shows poor OMMC grades and Polyester/Lycra (K2-UT) blend fabric shows fair OMMC

From the Table 5, it is observed that 5minute plasma treatment is optimum as giving higher one way transport index and overall moisture management capability grade in almost all the fabrics. It can be seen that OWTC grade and OMMC grades are higher for plasma pre-modified followed by chemical treated samples compared to untreated and commercial fabric samples indicating suitability of developed fabrics for effective moisture management properties required in sportswear application.

\section{Drying rate}

This drying rate test determines the drying rate of textile fabrics based on the evaporation rate at standard atmospheric conditions. This testing is based on measuring the weight of water content which is applied on the fabric for a particular time period by using a weighing balance and with drying rate software connected to it. Table 6 elaborates drying rate of 3 commercial fabrics and 16 developed fabrics. Drying rate of commercial garment is in the range of $0.29-0.38 \% / \mathrm{min}$.

Table 6: Drying Rate of commercial garments and developed fabrics.

\begin{tabular}{|c|c|}
\hline Sample Code & Dry Rate (\%/min) \\
\hline Commercial garment (CG-1) & 0.38 \\
\hline Commercial garment (CG-2) & 0.34 \\
\hline Commercial garment (CG-3) & 0.29 \\
\hline
\end{tabular}

grades. Commercial garment has fair to good OMMC properties. Plasma and chemically treated Polyester (K1A- K1C, K3A- K3C), Polyester/Lycra (K2A- K2C) fabric shows very good overall moisture management capability grade indicating that these fabrics can also be effectively used for sportswear application.

\begin{tabular}{|c|c|}
\hline K1- Untreated & 0.60 \\
\hline K1 - A & 0.32 \\
\hline $\mathrm{K} 1-\mathrm{B}$ & 0.25 \\
\hline $\mathrm{K} 1-\mathrm{C}$ & 0.21 \\
\hline K2 - Untreated & 0.47 \\
\hline K2 - A & 0.28 \\
\hline $\mathrm{K} 2-\mathrm{B}$ & 0.24 \\
\hline $\mathrm{K} 2-\mathrm{C}$ & 0.22 \\
\hline K3 - Untreated & 0.43 \\
\hline K3 - A & 0.34 \\
\hline K3 - B & 0.29 \\
\hline $\mathrm{K} 3-\mathrm{C}$ & 0.29 \\
\hline K4- Untreated & 0.57 \\
\hline $\mathrm{K} 4-\mathrm{A}$ & 0.29 \\
\hline $\mathrm{K} 4-\mathrm{B}$ & 0.26 \\
\hline $\mathrm{K} 4-\mathrm{C}$ & 0.21 \\
\hline
\end{tabular}




\section{Current Trends in Fashion Technology \& Textile Engineering}

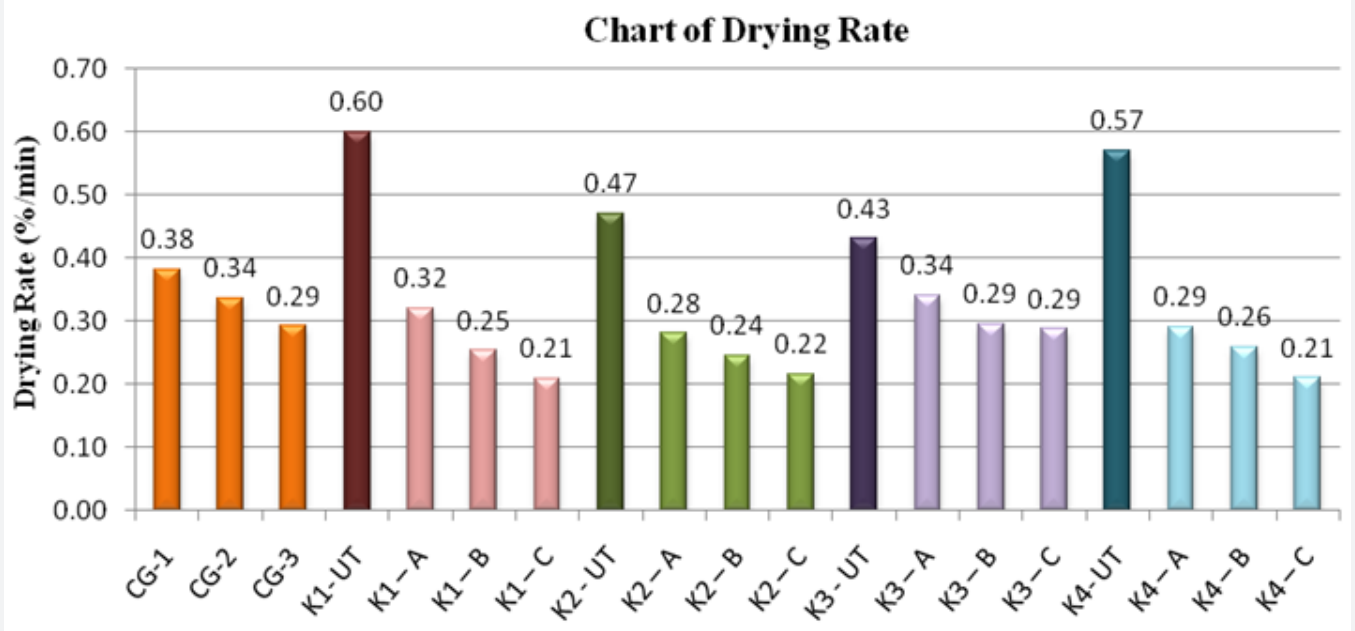

Figure 3: Drying rate of commercial garments and developed fabrics.

Figure 3 shows that untreated Polyester fabric shows drying rate of 0.60 and $0.43 \% / \mathrm{min}$ whereas Polyester/Lycra and Polyester/Cotton blend fabric shows drying rate of 0.47 and $0.43 \% / \mathrm{min}$ respectively. From the results it is observed that after plasma and chemical treatment drying rate of Polyester, Polyester/Lycra and Polyester/Cotton blend decreases. It is found that with the increase in plasma treatment time, the drying rate (\%) per minute decrease. It may be due to the more surface roughening of Polyester fabric resulting in more absorption of the hydrophilic chemicals. But even after considerable drop in drying rate of developed fabric their drying behavior are comparable with commercial garment. This indicates that plasma and chemically modified Polyester and Polyester blends show low drying rate compared to untreated fabrics but still they are suitable for sportswear application when compared with commercial garment.

\section{Conclusion}

Sportswear is a very vast and challenging field in which required functionality can be designed by suitable choice of raw materials, structure and geometry of fibers, yarns and fabrics, surface modification and garment assembly techniques. Moisture management properties like sweat absorption, sweat dissipation and faster drying are the primary desirable functions of high active sportswear which affects the comfort sensation of a player during a game. To achieve these properties, Polyester and Polyester/Lycra and Polyester/Cotton blend fabrics are treated with air plasma followed by a chemical treatment to enhance hydyophilicity. Plasma treatments help in surface roughening of Polyester. Plasma pre-modified knitted Polyester fabrics are given hydrophilic chemical treatment. The plasma treatment time of $5 \mathrm{~min}$ followed by chemical treatment is found to give the optimum results with respect to moisture management properties and drying rate. The study indicates that after plasma and finishing with hydrophilic finishing chemical; the Polyester fabrics shows enhance moisture management properties with moderate drying arte which makes it suitable for sportswear application. These modified and light weight moisture management fabrics will be helpful to keep the sportsman free from uncomfortable clinginess and it can also improve the performance of sportsperson.

\section{References}

1. Adanur S (1995) Handbook of Industrial Textiles, Wellington Sears, Technology and Engineering publishing.

2. Bendak A, El-Marsafi SM (1991) Effects of Chemical Modifications on Polyester Fibres. Journal of Islamic Academy of Sciences 4(4): 275-284.

3. Smith F, Mei W Fashion Applications for Polyester Fiber, Particularly Hydrophilic Polyester.

4. Duru SC, Candan C (2013) Effect of repeated laundering on wicking and drying properties of fabrics of seamless garments. Textile Research Journal 83(6): 591-605.

5. Sarkar M, Fan J, Szeto YC, Tao X (2009) Biomimetics of plant structure in textile fabrics for the improvement of water transport properties. Textile Research Journal 79(7): 657-668.

6. Su CI, Fang JX, Chen XH, Wu WY (2007) Moisture absorption and release of profiled polyester and cotton composite knitted fabrics. Textile Research Journal 77(10): 764-769.

7. Tai Lee Textiles Company, TLT - Our Moisture Management Technology.

8. Das B, Das A, Kothari VK, Fanguiero R, Araujo M (2007) Moisture transmission through textiles. Part II: evaluation methods and mathematical modeling. Autex Research Journal 7(3): 194-216.

9. Gorji M, Bagherzadeh R (2016) Moisture management behaviors of high wicking fabrics composed of profiled Fibres. Indian Journal of Fibre \& Textile Research 41(3): 318-324.

10. (2009) AATCC Test Method 195-009, Liquid Moisture management Properties of Textile Fabrics.

11. Troynikov O, Wardiningsih W (2011) Moisture management properties of wool/polyester and wool/bamboo knitted fabrics for the sportswear base layer. Textile Research Journal 81(6): 621-631.

12. Hu J, Li Y, Yeung KW, Wong AS, Xu W (2005) Moisture management tester: a method to characterize fabric liquid moisture management properties. Textile Research Journal 75(1): 57-62. 


(C) This work is licensed under Creative
Commons Attribution 4.0 Licens
DOI: $10.19080 /$ CTFTTE.2018.03.555625

\section{Your next submission with Juniper Publishers will reach you the below assets}

- Quality Editorial service

- Swift Peer Review

- Reprints availability

- E-prints Service

- Manuscript Podcast for convenient understanding

- Global attainment for your research

- Manuscript accessibility in different formats ( Pdf, E-pub, Full Text, Audio)

- Unceasing customer service

Track the below URL for one-step submission https://juniperpublishers.com/online-submission.php 